\title{
Parámetros Reproductivos del Ganado Nellore en la Selva Central del Perú (2000-2007)
}

\author{
Reproductive Parameters of Nellore Cattle in the Central Tropics \\ of Peru (2000-2007) \\ Doris Maritza Chirinos Peinado ${ }^{1,3}$, Jorge Isaac Castro Bedriñana, \\ Teodoro Calderón León ${ }^{2}$
}

\section{Resumen}

Con el objetivo de evaluar el estado de los principales parámetros reproductivos del ganado vacuno Nellore criado en una zona de la selva central del Perú, se evaluó la información reproductiva de 63 vacas que tuvieron tres partos consecutivos entre 2000 a 2007. Se evaluó la edad a la primera concepción, edad al primer parto, intervalo entre el primer, segundo y tercer parto, días vacíos entre el segundo y tercer parto y el peso al nacimiento de los cuatro primeros partos. La edad a la primera concepción fue de $30.7 \pm$ 6.0 meses (rango: 17.7-42.9 meses), edad al primer parto de 40.2 \pm 6.0 meses (rango: 27.252.4 meses), intervalo entre partos de 434.1 \pm 58.6 días (rango: 317-540 días), días vacíos de $179.8 \pm 55.5$ días (rango: $90-292$ días) y peso de las crías al nacimiento de $27.0 \pm 4.9 \mathrm{~kg}$ (rango: $20-40 \mathrm{~kg}$ ).

Palabras clave: Satipo, ganado tropical, intervalo entre partos, sistema de producción, reproducción animal

\section{AbSTRaCT}

The aim of this study was to assess the status of major reproductive parameters of Nellore cattle reared in the central tropics of Peru. Reproductive data of 63 cows that had three consecutive calvings between 2000 to 2007 was used. The variables were age at first conception, age at first calving, interval between the first, second and third calving, open days between second and third calving, and calf birth weight in the first four

${ }^{1}$ Facultad de Zootecnia, Universidad Nacional del Centro del Perú, Huancayo, Perú

${ }^{2}$ Departamento de Producción Agropecuaria, Instituto de Educación Superior Técnica «Jaime Cerrón Palomino», Huancayo, Perú

${ }^{3}$ E-mail: chirinosdoris@hotmail.com

Recibido: 29 de junio de 2016

Aceptado para publicación: 16 de diciembre de 2016 
parturitions. Age at first conception was $30.7 \pm 6.0$ months (range: 17.7 to 42.9 months), age at first calving was $40.2 \pm 6.0$ months (range: 27.2 to 52.4 months), calving interval was $434.1 \pm 58.6$ days (range: 317 to 540 days), open days was $179.8 \pm 55.5$ days (range: 90-292 days) and body weight at birth was $27.0 \pm 4.9 \mathrm{~kg}$ (range: $20-40 \mathrm{~kg}$ ).

Key words: Satipo, tropical cattle, calving interval, livestock production system, animal reproduction

\section{INTRODUCCIÓN}

El crecimiento poblacional obliga a tecnificar y modernizar los sistemas de producción animal, debiéndose mejorar los parámetros productivos y reproductivos de la ganadería tropical (Jainudeen y Hafez, 2000; Báez y Grajales, 2009; Chud et al., 2016), los cuales están afectados por una serie de factores adversos, principalmente la subalimentación (Ramírez-Avilés et al., 2007) ligada al periodo del año (Santana et al., 2012) y el inadecuado manejo reproductivo (Jainudeen y Hafez, 2000; Millen et al, 2011) y sanitario de los hatos (Savc et al., 2016).

La eficiencia reproductiva se puede evaluar a través de varios indicadores (Córdova y Pérez, 2002), siendo el intervalo entre partos (IEP), los días abiertos y los servicios por concepción, los que mejor describirían la eficiencia reproductiva del hato (Pérez-Hernández y Rojo, 2003). La meta ideal del programa reproductivo es lograr que todas las hembras tengan su primer parto a los 24 meses de edad y de allí para adelante una cría cada año (Ortiz et al., 2005; Buzanskas et al., 2013); no obstante, en ganado tropical se tiene un bajo desempeño reproductivo, caracterizado por edades tardías al primer parto (Millen et al., 2011; Diskin y Kenny, 2014), bajos porcentajes de concepción en el posparto y prolongado retorno al ciclo reproductivo (Roa 2006).

La eficiencia reproductiva del ganado Bos indicus es pobre comparada con el ganado Bos taurus; así, Perotto et al. (2006) reporta un intervalo entre partos sucesivos en ganado Nellore de Paraná (Brasil) de 466 \pm 20 días, mientras que para los cruces Guzerat x Nellore, Red Angus x Nellore, Marchigiana x Nellore y Simental x Nellore obtuvieron promedios de $485 \pm 22,385 \pm 29$, $432 \pm 30$ y $446 \pm 29$ días, respectivamente.

Magaña et al. (2002), trabajando con vacas cebú y sus cruces con ganado europeo, reportan un IEP de 300-390 días en el $49 \%$ de la población, entre 391-480 días en el $30 \%$, entre $481-570$ días en el $16 \%$ y de más de 570 días en el 5\% del rebaño. Este elevado IEP en el ganado Bos indicus se atribuye principalmente al mayor periodo de anestro posparto (Pérez-Hernández y Rojo, 2003) y en menor medida a problemas de mortalidad embrionaria, servicios infértiles o a interrupciones de la ciclicidad. Por su parte, García et al. (2003), en vacas Nellore, reportan 308 \pm 13.8 días de intervalo entre el parto al primer estro y de $369 \pm 15.5$ días de intervalo parto-concepción; asimismo, las vacas que lograron ciclar, requirieron entre 2 a 3 ciclos estrales para concebir.

El efecto del estado nutricional sobre la función reproductiva de los animales ha sido ampliamente documentado. Castro y Chirinos (2007) señalan que la reproducción es una función nutricional y la respuesta reproductiva depende del nivel nutricional de los animales. En épocas de abundante pasto acumulan reservas para ser movilizadas durante la época de escasez (Mejía-Bautista et al., 2010), pudiendo presentarse un balance energético negativo cuyo punto máximo se conoce como «nadir» (Butler, 2000); situación que afecta 
el comportamiento reproductivo y se asocia con el bajo peso al nacimiento, anestro postarto y concentraciones bajas de $\mathrm{GnRH}$ y de LH, entre otros (Báez y Grajales, 2009). Por su parte, Sartori et al. (2016) indican que las diferencias en la función ovárica relacionadas con la nutrición son consistentes y podrían deberse a la influencia de hormonas metabólicas, como la insulina y el factor de crecimiento insulínico 1.

Con respecto al peso al nacimiento en ganado Nellore, se reportan pesos promedio entre 29 y $32 \mathrm{~kg}$ (Silva et al., 2008; Santana et al., 2012; Boligon et al., 2013; Chud et al., 2014).

En base a lo indicado, este estudio descriptivo retrospectivo tuvo como objetivo evaluar el estado de los principales parámetros reproductivos del ganado Nellore criado en Satipo, zona representativa de la selva peruana; entre ellos, la edad a la primera concepción y al primer parto, el intervalo entre partos, el promedio de días vacíos y el peso promedio al nacimiento, sistematizando datos de tres partos consecutivos, registrados entre los años 2000-2007, con el propósito de brindar evidencia científica para la formulación de planes de acción tendiente a mejorar la eficiencia del sistema de producción de ganado Nellore en condiciones de selva central.

\section{Materiales y Métodos}

\section{Lugar de Estudio}

Los datos utilizados en este estudio fueron proporcionados por el Programa de Ganadería Tropical de la Universidad Nacional del Centro del Perú, principal centro de crianza de ganado Nellore de la Selva Central. Este centro de producción dota de ganado a los pequeños criadores de la zona, y se encuentra ubicado en el distrito de Río Negro, provincia de Satipo, departamento de Junín, perteneciente a la ecoregión Selva Alta. La zona se encuentra a $640 \mathrm{msnm}$, presenta una precipitación pluvial anual de $1200 \mathrm{~mm}, 78 \%$ de humedad relativa y una temperatura promedio anual de $24^{\circ} \mathrm{C}$.

\section{Población y Muestra}

La población en estudio estuvo dada por 130 bovinos raza Nellore pertenecientes al programa de ganadería tropical antes indicado. La muestra consideró a 63 vacas que tuvieron registros de tres partos consecutivos entre los años 2000 y 2007. Se excluyeron de la muestra las vacas con menos de tres partos en el periodo estudiado y aquellas con información incompleta.

\section{Alimentación y Manejo Animal}

El centro de producción cuenta con 32 ha de pastos cultivados, dispuestos en 12 potreros de diverso tamaño; empleándose una carga de 3 cabezas/ha/año. El ganado pastorea diariamente 8 a 9 horas en potreros con Brachiaria decumbens, B. brizanta, pasto castilla (Panicum maximun) y pasto elefante (Pennisetum purpureum).

Se utiliza un sistema de producción extensivo, con empadre a monta natural controlada, con dos toros, durante todo el año. Las vaquillas entran al primer empadre a los $300 \mathrm{~kg}$ de peso vivo (aproximadamente a los 19 meses de edad). El programa sanitario comprende dosificaciones contra parásitos internos y externos una vez al año, de acuerdo al calendario que maneja el centro de producción.

\section{Parámetros Reproductivos}

Se determinó la edad a la primera concepción (considerando un periodo de gestación de 282 días), la edad al primer parto, y con base a información de los tres primeros partos se determinó el intervalo entre partos, los días vacíos y el peso al nacimiento. Estos índices reproductivos se determinaron empleando las fórmulas recomendadas por 
Cuadro 1. Principales parámetros reproductivos del ganado Nellore criado en Río Negro, Satipo, Perú (2000-2007)

\begin{tabular}{|c|c|c|c|c|}
\hline Variable reproductiva & Promedio & D.E. & Mínimo & Máximo \\
\hline Edad a la primera concepción (meses) & 30.72 & 6.01 & 17.66 & 42.93 \\
\hline Edad al primer parto (meses) & 40.22 & 6.01 & 27.16 & 52.43 \\
\hline Peso de la $1^{\mathrm{a}}$ cría al nacimiento $(\mathrm{kg})$ & 26.13 & 5.42 & 20 & 40 \\
\hline Intervalo al segundo parto (días) & 458.47 & 112.25 & 291 & 712 \\
\hline Días vacíos al segundo parto (días) & 202.94 & 101.09 & 64 & 430 \\
\hline Peso de la $2^{\mathrm{a}}$ cría al nacimiento $(\mathrm{kg})$ & 27.62 & 4.81 & 20 & 38 \\
\hline Intervalo al tercer parto (días) & 406.16 & 73.37 & 316 & 584 \\
\hline Días vacíos al tercer parto (días) & 151.6 & 65.03 & 68 & 302 \\
\hline Peso de la $3^{\text {a }}$ cría al nacimiento $(\mathrm{kg})$ & 26.21 & 4.04 & 20 & 36 \\
\hline Peso de la $4^{\mathrm{a}}$ cría al nacimiento $(\mathrm{kg})$ & 27.88 & 5.22 & 20 & 44 \\
\hline Peso promedio de crías al nacimiento ${ }^{1}$ & 26.96 & 4.87 & 20 & 39.5 \\
\hline Intervalo entre partos ${ }^{2}$ & 432.32 & 92.81 & 303.5 & 648 \\
\hline Días vacíos ${ }^{2}$ & 177.27 & 83.06 & 66 & 366 \\
\hline
\end{tabular}

${ }^{1}$ Promedio de la primera a la cuarta cría

${ }^{2}$ Promedio entre el segundo y tercer parto

Jainudeen y Hafez (2000), calculados como el promedio del desempeño individual (Ortiz et al., 2005).

\section{Análisis de Datos}

La matriz de datos consideró información de 63 registros individuales de vacas Nellore, con los tres primeros partos consecutivos entre los años 2000 al 2007; información que fue sistematizada y procesada en el software SPSS v.18. Se determinaron los principales estadísticos descriptivos de tendencia central y de dispersión de los parámetros reproductivos considerados en la evaluación.

\section{Resultados y Discusión}

En el Cuadro 1 se resumen los estadísticos descriptivos de las variables reproductivas evaluadas en ganado Nellore criado en la selva central de Satipo.
Cuadro 2. Edad (en meses) a la primera concepción en ganado Nellore

\begin{tabular}{cc}
\hline $\begin{array}{c}\text { Edad a la primera } \\
\text { concepción }\end{array}$ & $\begin{array}{c}\text { Frecuencia } \\
(\%)\end{array}$ \\
\hline $17-24$ & 11.0 \\
$24-30$ & 39.7 \\
$30-36$ & 28.6 \\
$>36$ & 20.6 \\
\hline
\end{tabular}

Cuadro 3. Edad (en meses) al primer parto en ganado Nellore

\begin{tabular}{cc}
\hline Edad al primer parto & $\begin{array}{c}\text { Frecuencia } \\
(\%)\end{array}$ \\
\hline $27-30$ & 3.2 \\
$30-36$ & 19.0 \\
$36-42$ & 38.1 \\
$>42$ & 39.7 \\
\hline
\end{tabular}


Cuadro 4. Frecuencia (\%) del intervalo entre partos (días) en vacas Nellore

\begin{tabular}{ccc}
\hline $\begin{array}{c}\text { Intervalo entre } \\
\text { partos }\end{array}$ & $1^{\circ}-2^{\circ}$ parto & $\begin{array}{c}2^{\circ}-3^{\circ} \\
\text { parto }\end{array}$ \\
\hline$<300$ & 1.9 & 0 \\
$300-390$ & 30.2 & 46.5 \\
$391-480$ & 32.1 & 34.9 \\
$481-570$ & 15.1 & 14.0 \\
$>570$ & 20.8 & 4.7 \\
\hline
\end{tabular}

Cuadro 5. Frecuencia (\%) del número de días vacíos en el segundo y tercer parto de vacas Nellore

\begin{tabular}{ccc}
\hline Días vacíos & $\begin{array}{c}\text { Segundo } \\
\text { parto }\end{array}$ & $\begin{array}{c}\text { Tercer } \\
\text { parto }\end{array}$ \\
\hline $60-90$ & 9.4 & 14.0 \\
$91-120$ & 11.3 & 20.9 \\
$121-150$ & 22.6 & 34.9 \\
$151-180$ & 13.2 & 7.0 \\
$181-210$ & 3.8 & 4.7 \\
$>210$ & 39.6 & 18.6 \\
\hline
\end{tabular}

En el Cuadro 2 se presenta la distribución porcentual de la edad a la primera concepción. El valor promedio supera los promedios reportados por Eler et al. (2014) y Buzanskas et al. (2016) de 23 y 26 meses, respectivamente. Estos resultados son importantes de considerar, porque la edad a la primera concepción y al primer parto reflejan la velocidad de crecimiento de la hembra y la edad a la pubertad, cuya presentación tardía reduce el valor económico del animal, al disminuir el número potencial de descendientes producidos en su vida útil (Grajales et al., 2006).
En el Cuadro 3 se presenta la distribución porcentual de la edad al primer parto. La edad promedio fue mayor a los valores encontrados por otros autores, como Pereira et al. (2001), Eler et al. (2014) y Buzanskas et al. (2016), quienes en ganado Nellore criados en Brasil, reportaron edades promedio al primer parto de $37.1,32.7$ y 35.2 meses, respectivamente. Esta variable afecta la productividad animal, puesto que las hembras llegarían a tener menos partos de los esperados. Se entiende que, si las vacas tienen su primera cría a una edad temprana, destetarán crías de buen peso, mantendrán el mínimo de días entre partos y tendrán más crías durante su ciclo productivo (Veneciano y Frasinelli, 2014). La edad al primer parto podría ser reducida a través de mejoras de alimentación y del manejo posdestete de las novillas.

El IEP promedio al segundo parto por encima de los 450 días en este estudio estuvo por debajo de los $492 \pm 22$ días reportado por Perotto et al. (2006) para ganado Nellore criado en Paraná, Brasil. El IEP determinado en este estudio para los tres primeros partos fue similar a $\operatorname{los} 466 \pm 20$ días reportados por Perotto et al. (2006), lo cual podría indicar que la eficiencia reproductiva del hato evaluado se encuentra dentro los valores reportados para esta raza (Cuadro 4).

Los promedios de días vacíos al segundo y tercer parto superaron los 200 y 150 días, respectivamente (Cuadro 1). El promedio de días vacíos, considerando la información acumulada del segundo y tercer parto (177.3 \pm 83.1 días) fue muy superior al rango óptimo indicado por Ortiz et al. (2005) entre 85 y 110 días. Asimismo, señalan que menos del $10 \%$ de las vacas deben pasar de 120 días vacíos, resultando en el presente estudio que el $62.5 \%$ de las vacas superaron los 120 días vacíos. La distribución porcentual del número de días vacíos en el segundo y tercer parto se presentan en el Cuadro 5.

El peso promedio de las crías primerizas determinado en este estudio $(27.0 \pm 4.9$ $\mathrm{kg}$ ) fue inferior a los reportados es estudios 
realizados en Brasil, como el de Silva et al. (2008) en crianzas de Paraná, Santa Catarina y Río Grande do Sul con promedios de $30.4 \pm$ $2.4,29.1 \pm 2.9$ y $29.8 \pm 2.9 \mathrm{~kg}$, respectivamente. Asimismo, Santana et al. (2012), Bolingon et al. (2013) y Chud et al. (2014), refieren pesos promedio al nacimiento de 30.9 $\pm 4.0,32.4 \pm 3.9$ y $32.2 \pm 3.8 \mathrm{~kg}$, respectivamente. No obstante, es importante señalar que el peso promedio determinado en este estudio estuvo en el rango de parámetros que la Asocebu-Colombia (2016) refiere para ganado Nellore, que está entre 26 a $28 \mathrm{~kg}$.

\section{Agradecimiento}

Al personal del centro de producción, por su apoyo en la fase de campo del presente estudio. La principal fuente financiera del estudio fue el Fondo Especial de Desarrollo Universitario.

\section{Literatura Citada}

1. Asocebú-Colombia. 2016. Parámetros en Nelore. Ficha técnica. [Internet]. Disponible en: http://www.asocebu.com/ index.php/el-cebu/razas/nelore

2. Báez SG, Grajales LH. 2009. Anestro postparto en ganado bovino en el trópico. Rev MVZ Córdoba 14: 1867-1875.

3. Boligon AA, Bignardi $A B$, Mercadante MEZ, Lôbo RB, Albuquerque LG. 2013. Principal components and factor analytic models for birth to mature weights in Nellore cattle. Livest Sci 152: 135-142. doi: 10.1016/j.livsci.2013.01.005

4. Butler WR. 2000. Nutritional interactions with reproductive performance in dairy cattle. Anim Reprod Sci 60-61: 449-457. doi: 10.1016/S03784320(00)00076-2

5. Buzanskas ME, Savegnago RP, Grossi DA, Venturini GC, Queiroz SA, Silva LOC, Torres Júnior RAA, et al. 2013. Genetic parameter estimates and principal component analysis of breeding values of reproduction and growth traits in female Canchim cattle. Reprod Fertil Dev 25: 775-781. doi: 10.1071/RD12132

6. Buzanskas ME, Pires PS, Chud TCS, Bernardes PA, Rola LD, Savegnago RP, et al. 2016. Parameter estimates for reproductive and carcass traits in Nelore beef cattle. Theriogenology 92 : 204-209. doi: 10.1016/j.theriogenology.2016.09.057

7. Castro J, Chirinos D. 2007. Nutrición animal. Huancayo, Perú: Ind Gráfica. $223 \mathrm{p}$.

8. Córdova IA, Pérez GJF. 2002. Indicadores reproductivos de bovinos en el trópico mexicano y factores que lo determinan. Med Vet 19: 47-56.

9. Chud TCS, Caetano SL, Buzanskas ME, Grossi DA, Guidolin DGF, Nascimento GB, et al. 2014. Genetic analysis for gestation length, birth weight, weaning weight, and accumulated productivity in Nellore beef cattle. Livest Sci 170: 16-21. doi: 10.1016/j.livsci.2014.09.024

10. Diskin MG, Kenny DA. 2014. Optimising reproductive performance of beef cows and replacement heifers. Animal 8: 27-39. doi: 10.1017/S175173111400086X

11. Eler JP, Bignardi AB, Ferraz JBS, Santana ML. 2014. Genetic relationships among traits related to reproduction and growth of Nelore females. Theriogenology 82: 708-714. doi: 10.1016/j.theriogenology.2014.06.001

12. García GA, Maldonado-Estrada JG, López JG. 2003. Caracterización productiva y reproductiva de las explotaciones ganaderas del bajo Cauca y el litoral atlántico antioqueños. II. Comportamiento de cuatro grupos raciales Bos indicus en un sistema de bosque seco tropical (bs-T). Rev Col Cienc Pec 16: 117-125.

13. Grajales H, Hernández A, Prieto E. 2006. Edad y peso a la pubertad y su relación con la eficiencia reproductiva de grupos raciales bovinos en el trópico colombiano. Livest Res Rural Dev 18. 
[Internet]. Disponible en: http:// www.lrrd.org/lrrd18/10/graj18139.htm

14. Jainudden MR, Hafez ESE. 2000. Ciclos reproductivos en bovinos y búfalos. En: Hafez ESES, Hafez B (eds). Reproducción e inseminación artificial en animales. $7^{\mathrm{a}}$ ed. México: McGraw Hill. p 163-167.

15. Magaña JG, Delgado R, Segura JC. 2002. Factores ambientales y genéticos que influyen en el intervalo entre partos y el peso al nacer de ganado Cebú en el sureste de México. Rev Cub Cienc Agríc 33:317-322.

16. Mejía-Baustista GT, Magaña JG, Segura-Correa JC, Delgado R, EstradaLeón RJ. 2010. Comportamiento reproductivo y productivo de vacas $B o s$ indicus, Bos taurus y sus cruces en un sistema de producción vaca:cría en Yucatán, México. Trop Subtrop Agroecosyst 12: 289-301.

17. Millen DD, Pacheco RDL, Meyer PM, Rodrigues PHM, Arrigoni MB. 2011. Current outlook and future perspectives of beef production in Brazil. Anim Front 1(2): 46-52. doi:10.2527/af.2011-0017

18. Ortíz SJA, García TO, Morales TG. 2005. Manual para el manejo de bovinos reproductores de leche. México: Secretaría de Reforma Agraria de México. $53 \mathrm{p}$.

19. Pereira E, Eler J, Costa F, Ferraz J. 2001. Análise genética da idade ao primeiro parto e do perímetro escrotal em bovinos da raca Nelore. Arq Bras Med Vet Zoot 53: 1116-121. doi: 10.1590/ S0102-09352001000100019

20. Pérez-Hernández P, Rojo RR. 2003. Necesidades de investigación y transferencia de tecnología de la cadena de bovinos de doble propósito en el Estado de Veracruz. Tepetales. FUNPROVER. 151 p. [Internet]. Disponible en: http:// www.cofupro.org.mx/cofupro/ Publicacion/Archivos/penit110.pdf

21. Perotto D, dos Santos Abrahão JJ, Kroetz IA. 2006. Intervalo de partos de fêmeas bovinas Nelore, Guzerá x Nelore, Red Angus x Nelore, Marchigiana $\mathrm{x}$
Nelore e Simental x Nelore. R Bras Zootec 35: 733-741. doi: 10.1590/S151635982006000300014

22. Ramírez-Avilés L, Ku-Vera JC, Alayón GJ. 2007. Follaje de árboles y arbustos en los sistemas de producción bovina de doble propósito. Arch Latinoam Prod Anim 15: 251-264.

23. Roa AN. 2006. El manejo reproductivo de bovinos de doble propósito en las condiciones del llano venezolano. Rev INIA Divulga, Maracay N. ${ }^{\circ}$ 7: 50-54.

24. Santana ML, Eler JP, Cardoso FF, Albuquerque LG, Bignardi AB, Ferraz JBS. 2012. Genotype by environment interaction for birth and weaning weights of composite beef cattle in different regions of Brazil. Livest Sci 149: 242249. doi: 10.1016/j.livsci.2012.07.017

25. Sartori R, Gimenes LU, Monteiro Jr PL, Melo LF, Baruselli PS, Bastos MR. 2016. Metabolic and endocrine differences between Bos taurus and Bos indicus females that impact the interaction of nutrition with reproduction. Theriogenology 86: 32-40. doi: 10.1016/ j.theriogenology.2016.04.016

26. Savc M, Duane M, O'Grady LE, Somers JR, Beltman ME. 2016. Uterine disease and its effect on subsequent reproductive performance of dairy cattle: a comparison of two cowside diagnostic methods. Theriogenology 86: 1983-1988. doi: 10.1016/j.theriogenology.2016.06.018

27. Silva LJ, Rorato PRN, Weber T, Boligon AA, Comin JG, Dornelles MA, 2008. Efeito da interação genotipo $\mathrm{x}$ ambiente sobre o peso ao nascimento, aos 205 e aos 550 dias de idade de bovinos da raça Nelore na Região Sul do Brasil. R Bras Zootec 37: 54-60. doi: 10.1590/S1516-35982008000100007

28. Veneciano JH, Frasinelli CA. 2014. Cría y recría de bovinos. INTA San Luis. [Internet]. Disponible en: http:// www.produccionbovina.com/ informacion_tecnica/cria/177TextoCriaRecria.pdf 